the nuclei counted. A closer examination of these nuclei usually revealed a degree of irregularity of the nuclear membrane. As there appears to be a concurrence between the incidence of sex-chromatin in fotal cells and the presence of ovarian characters in the gonad, young embryos in which the gonad had not yet differentiated into a testis or ovary were examined. Thirteen embryos were suitable for this examination, and six were found to possess a sufficient number of nuclei containing sex-chromatin to warrant their classification as females. The youngest specimen showing this feature was a $1.7 \mathrm{~mm}$, pre-somite embryo. In addition, the syneytiotrophoblast cells of an implanting blastocyst were seen to contain the sex-chromatin particles, although the cells of the embryonic disk and the cytotrophoblast were not suitable for the test.

'These results are presented as they appear to be significant, and the method may prove useful in the determination of sex in early embryos. It is realized, however, that more specimens will have to be examined and more experience gained before the test can be said to be entirely reliable.

Department of Anatomy,

$$
\text { T. W. Glenister }
$$

Charing Cross Hospital Medical School, London, W.C.2.

May 11.

1 Barr, M. L., Surg. Gynec. Obstet., 99, 184 (1954) ; Anat. Rec., 121' 387 (1955).

2 Barr, M. L., and Bertram, E. G., Nature, 168, 676 (1949); J. Anat., 85, 171 (1951).

${ }^{3}$ Barr, M. L., Bertram, E. G., and Lindsay, H. A., Anat. Rec., 107, $283(1950)$.

4 Dixon, A. D., and Torr, J. B. D., Communication to Anat. Soc.

5 Graham, M. A., Nature, 173, 310 (1954).

- Graham, M. A., and Barr, M. L., Anat. Rec., 112, 709 (1952).

'Marberger, E., Bocciabelbe, R. A., and Nelson, W. O., Proc. Soc. Exp. Biol. Med., 89, 488 (1955).

${ }^{8}$ Moore, K. L., and Barr, M. L., J. Comp. Neurol., 98, 213 (1953); Acta Anat., 21, 197 (1954); 'Lancet, ii, 57 (1955).

- Moore, K. L., Graham, M. A., and Barr, M. L., Surg. Gynec. Obstet., 641 (1953).

${ }^{10}$ Fuchs, F., and Riis, P., Nature, 177, 330 (1956).

\section{Effect of Electric Shock and Cardiazol Shock on Morphine Tolerance}

DURING my investigation of the tolerance for morphine and codeine using 'coughing dogs'1, I noted that acquired tolerance for these drugs by which their antitussive effects were completely lost was reduced or eliminated by an electric shock or a cardiazol shock. Morphine (2-6 mgm. $/ \mathrm{kgm}$.) given intravenously completely depressed coughing for 1-6 hr. in such dogs on the first day of administration. By continued daily application of the drug, the dogs acquired tolerance in five to ten days; but the same drug failed to depress coughing afterwards. Similar tolerance for codeine developed in eight to fourteen days. The dogs thus made tolerant for morphine or codeine were subjected to an electric shock (a.c. 90-100 V., 2 sec.) or cardiazol shock (30-50 mgm./ $\mathrm{kgm}$.). On the following day, each antitussive drug was one-fourth to three-fourths as potent, or in a few cases, quite as potent, as on the first day of administration, indicating that the shock had reduced or eliminated the tolerance.

The effect of the first shock persisted for three to four days, after which another shock was required to eliminate the redeveloped tolerance. Neither of the shock therapies affected the antitussive action of morphine in any non-tolerant dogs, and the combined application of morphine and electric shock for many consecutive days failed to prevent the animals from acquiring tolerance for morphine. Excepting the rare cases, the effect of an electric shock or cardiazol shock was proportional to the severity of the resulting convulsion and excitement.

From the following observations it is presumed that the effect of shock may in part be ascribed to the increased permeability of cerebral blood vessels and brain tissue. (1) Intravenously administered trypan blue, which left brain and spinal tissue unstained in normal $\operatorname{dogs}^{2}$, stained brain tissue blue when accompanied by an electric shock (however, the nerve cells contained none of the dyestuff). (2) Hyaluronidase (10,000 v.r.u./kgm.) mixed with morphine reduced tolerance without causing convulsions, though the effect was far weaker than that of an electric shock. Brain tissue was also stained with trypan blue during hypertension produced with adrenaline; but the hypertension itself did not reduce the tolerance for morphine.

These facts suggest that the staining of brain tissue with trypan blue after application of an electric shock is mainly attributable to enhanced permeability of cerebral blood vessels due to the hypertension induced by convulsion, and that the effect of the shock on morphine tolerance may be based on its action of enhancing the permeability of brain tissue (especially the nerve cells themselves). Possibly the effect of shock therapy on a narcotic addict is in part based on the reduction of drug tolerance described above.

Further investigations have shown that : (1) toler. ance can be acquired only when morphine reaches the central nervous system via blood vessels, and not via the cisterna cerebellomedullaris, for the tolerance developed in five to fourteen days by intravenous or intra-arterial injection (common carotid artery), but never developed by daily intracisternal injection for six months; (2) when complete tolerance was obtained by daily intravenous administration of such a dose of morphine that would give much longer duration of antitussive effect than that given intracisternally, the same dose as that administered intracisternally before was given into the cisterna again; however, tolerance did not affect the intracisternal effect, that is, the intracisternal effect was almost equal to that before tolerance had been acquired.

Chemico-Pharmacological Department,

Y. KASÉ Faculty of Pharmacy,

University of Kumamoto, Kumamoto, Japan.

${ }^{1}$ Kasé, Y., Jap. J. Pharmacol., 4, 130 (1955).

${ }^{2}$ Goldman, E. E., "Vitalfarbung am Zentralnervensystem" (Georg Reimer, Berlin, 1913)

\section{Hair-line Cracks in Low-alloy Steels}

TнE cause of hair-line cracks in low-alloy steels has been debated for many years. The main hypotheses now current can be reduced to the following : the hydrogen-pressure hypothesis and the residual stress hypothesis. It follows from the former that hydrogen alone can induce hair-line cracks to form ; and from the latter that, in the absence of residual stress, no hair-line cracks will form even if hydrogen is present. 